\title{
CURRÍCULO ESCOLAR E PRÁTICAS ESCOLARES DE PROFESSORAS SOBRE OS SABERES CULTURAIS DA AMAZÔNIA BRAGANTINA
}

\author{
SCHOOL CURRICULUM AND SCHOOL PRACTICES OF TEACHERS ON CULTURAL KNOWLEDGE OF \\ BRAGANTINA AMAZON
}

Deyverson Luener de Oliveira Ferreira'

Ana Paula Vieira de Souza²

Resumo: O presente estudo busca trazer as concepções das professoras que atuam em uma escola da comunidade tradicional da Amazônia Bragantina sobre o currículo escolar, as práticas escolares e os saberes culturais. O trabalho analisa a relação entre os saberes culturais da comunidade da Vila-Que-Era, com o currículo escolar e as práticas vivenciadas pelas professoras que atuam na escola da comunidade. A pesquisa é de uma abordagem do tipo qualitativa por se tratar de articular entre sujeitos interlocutores e objeto estudado. Para a coleta dos dados, os dados primários foram originados pelo roteiro de entrevista e organizados pela técnica da análise de conteúdo, com a utilização de recursos tecnológicos, como gravador, para obter os relatos das professoras, bem como foram usados registros fotográficos e registros de diário de campo; os dados secundários, por sua vez, são levantados na revisão bibliográfica, a fim de situar quais os estudos já realizados na área estudada. Participaram da pesquisa os interlocutores representando a escola e a comunidade, duas professoras e o líder Comunitário. Os achados do estudo revelam a existência de fatores que dificultam um currículo articulado com os saberes culturais da comunidade, bem como os aspectos físicos, didáticos, estruturais e de formação continuada, além de um currículo que segue uma conduta imposta pela Secretaria de Educação Municipal.

Palavras-chave: Currículo. Prática Escolar. Saberes culturais. Comunidade Tradicional.
Abstract: This study brings the conceptions of teachers who work in a school of the Traditional Community of Bragantina Amazon about the school curriculum, school practices and cultural knowledge. The paper analyzes the relationship between the cultural knowledge of the traditional community Vila-Que-Era, and school curriculum and the practices experienced by teachers who work in the school of the community. The research is a qualitative approach because of the social phenomenon which gets a new meaning by the discourse of people. For data collection, the primary data were originated by interview script and organized by the technique of content analysis, using technological resources, as a recorder, to obtain the teachers' reports, as well as photographic records and field diary; the secondary data, on the other hand, are raised in the literature review in order to locate which studies have already been done in this field. Interlocutors representing the School and the Community, two Teachers and the Community Leader attended the research. The findings of the study reveal the existence of factors that make difficult a curriculum articulated with the cultural knowledge of the Community, as well as the physical, didactic and structural aspects; as the curriculum follows a conduct imposed by the Municipal Department of Education. The research also shows the relevance of teacher training and continuing education to work in the context of rural schools

Keywords: Curriculum. School practice. Cultural knowledge. Traditional Community.

\footnotetext{
1 Mestrando do Programa de pós-graduação em Linguagens e Saberes na Amazônia, Na Linha de pesquisa: Educação, Linguagens e Culturas na Amazônia pela Universidade Federal do Pará (2019 - Em andamento). Professor do Centro Universitário Planalto do Distrito Federal- UNIPLAN, Unidade de Bragança- PA. E-mail: deyversonluener@gmail.com. Orcid: https://orcid.org/0000-0001-6160-8034

2 Professora da Universidade Federal do Pará do Campus Universitário de Bragança e do Programa Linguagens e Saberes na Amazônia (PPLSA) na Linha de Educação, Linguagens e Culturas na Amazônia. Pesquisadora do Grupo de Estudos e Pesquisa Trabalho e Educação (GEPTE/NEB/UFPA) e do Núcleo Infâncias em Bragança-PA, E-mail: paulladesa@ufpa.br. Orcid: https://orcid.org/0000-0003-3340-1866.
} 
ISSN 1983-1579

Doi: 10.22478/ufpb.1983-1579.2020v13n1.51278

http://periodicos.ufpb.br/ojs2/index.php

\section{CONVERSAS INICIAIS}

O currículo escolar e práticas escolares de professores sobre os saberes culturais em uma escola da Amazônia Bragantina é o objeto de estudo desta pesquisa. Teoricamente, opta-se por compreender o currículo como lugar de discussões acerca do conhecimento nas interações sócio histórico, como conjunto pedagógico planejado com finalidade educativa e de transformação social na vida do aluno, em negação ao currículo prescrito na reprodução de uma ideologia hegemônica, o currículo oculto como o resultado da transmissão social e política do status quo.

Compreende-se o currículo escolar como as experiências escolares, que transitam por um longo processo histórico e social, de possibilidades historicamente, um campo de lutas travadas em busca de um ideal para cada contexto histórico. Nessa conjuntura, a educação do campo tem mostrado ser este espaço de controvérsias e lutas, em que o movimento social de professores e pesquisadores têm se debruçado no sentido de elucidar seus contornos, desenvolver propostas pedagógicas próximas da realidade dos alunos de comunidades tradicionais.

As propostas pedagógicas curriculares movimentadas pelo currículo crítico têm sido relevantes por permitir a compreensão de práticas de currículo e ensino de modo contextual, como parte de um todo concreto e complexo contexto. Sendo objetivos de concepção de educação, os procedimentos, a avaliação, os valores a serem construídos, as identidades, respeito a diversidade e as relações sociais que compõem o contexto pedagógico. Cada contexto histórico desencadeou uma forma diferente de definir o que é o currículo, sempre sendo esse o alvo de estudos para todos aqueles que buscavam entender e analisar os processos educativos.

O campo teórico do currículo crítico permeia por diferentes linhas de teorizações que estruturam os estudos dos contextos educativos. O currículo não é uma estruturação transcendente e fora de seu tempo, ele tem uma história, a qual vincula-se às formas específicas de organização da sociedade - em uma construção cultural -, organizando e estruturando a educação (MOREIRA; SILVA 1990).

O currículo como prática escolar modela a conjuntura da educação, sendo não só uma base teórica, mas também material e ideológica. Ele concretiza os fins sociais, culturais e científicos atribuídos à escolarização, sendo um reflexo do modelo educativo a ser determinado, bem como uma instrumentalização concreta que faz da escola um determinado sistema social (SACRISTÁN, 2000).

A escola necessita pensar o currículo pelo viés cultural, da diversidade, como construção sóciohistórica, sociocultural da/para as diferenças. Para isso, desvelar um currículo que possibilite compreender os alunos da escola do campo, propondo a eles que vivenciem rotinas diversificadas, coerentes com a realidades locais. Nessas localidades existe uma grande pluralidade de saberes culturais introduzido na vida desses alunos, sendo importante pensar como trazer essa realidade para dentro de uma proposta educativa. A concepção de saberes culturais transita por um complexo campo de teorização, existindo diferentes formas de definir as formas de saberes culturais. A palavra "saber" desencadeia um entendimento de ter conhecimento específico, ter certeza das coisas, ter habilidade, poder de explicar um fenômeno, poder de memorização, considerar, e praticar seus saberes no âmbito da prática. Sendo importante considerar que os saberes culturais configurassem, como diferentes formas de conhecimentos, construídos e repassados ao longo do tempo, ganhando novas representações com o passar do tempo e das gerações entre os parentescos.

Os saberes culturais transitam por diferentes perspectivas, sendo saberes que são transpassados de forma geracional, através das narrativas e das práticas repassadas aos sujeitos mais novos. Saberes culturais que tem significância para as comunidades tradicionais, pois ao longo do tempo foram e são as formas de atribuir a vivência das pessoas que estão nessas localidades. Esses saberes são atribuídos em diversas representações; formas de oralidade, capacitação de forma laboral, vínculo entre o local e o território, sendo saberes atribuídos nas práticas em famílias e em comunidade, não sendo uma forma formativa e intelectual, mas de socialização e interação (FERNANDES; FERNANDES; 2015). 
A escola da Comunidade da Vila-Que-Era, área de estudo, situada fora do perímetro urbano do Município de Bragança, organizada na perspectiva da educação do campo, adota o currículo pautado no campo, tendo como relevância a relação entre os saberes culturais e os conhecimentos escolares. A escola trabalha com classes multisseriadas, sendo importante problematizar uma educação com classes de diferentes perfis ao mesmo tempo, além do mais, das dificuldades em planejar as aulas e articular os materiais didáticos para uma turma homogênea.

Isto posto, a questão problema que guiou a pesquisa, se inscreve em saber, de que forma os professores, inseridos na escola da comunidade da Vila-Que-Era, interage com os saberes culturais vivenciados pelos estudantes no currículo escolar?

Partindo da hipótese que muitos professores que chegam para trabalhar na comunidade não possuem experiências sobre os saberes culturais local, vivenciados pelos alunos e moradores. A prática docente ainda é influenciada pelos processos de universalização do ensino; muitas vezes padronizados em relação ao currículo, adotam os conteúdos praticados nos centros urbanos, fora do contexto social da comunidade, sem mediar os saberes culturais com os conhecimentos escolares.

\section{CURRÍCULO ESCOLAR E PRÁTICAS ESCOLARES}

Ao trazer a discussão do currículo como práticas escolares faz-se importante definir currículo. Sendo uma construção que atravessa um contexto histórico, político, social, econômico e outras situações no campo das políticas curriculares. Para Sacristán (2000) o currículo é uma prática educativa, uma prática que menciona o currículo em uma realidade presente e estabelecida por meio das ações didáticas, políticas, administrativas e econômicas; sendo necessário prudência sobre qualquer colocação frente às práticas curriculares dentro dos espaços escolares.

O currículo como um campo sistemático de trabalho na educação, segundo Moreira (1990), dar-se devido às mudanças sociais que emergiram com o advento da sociedade industrial e urbana. Para o autor, as origens do pensamento curricular no Brasil têm origem na década de 20 e 30 do Século XX, quando importantes transformações econômicas e sociais, culturais e políticas e ideológicas eram processadas no país. Então, trazer a reflexão do currículo, como prática escolar, no Brasil é dialogar sobre muitas questões existentes tanto no campo educacional quanto no campo social.

O currículo desenvolve uma estruturação do que se vai trabalhar nos espaços escolares e fundamenta o que é necessário para o aluno aprender em seu processo formativo. Além disso, deve estabelecer estruturas do que irá acontecer dentro dos espaços escolares por meio de um planejamento proposto pelos sistemas educativos e a escola. Ao se associar o currículo aos conteúdos e disciplinas trabalhados nos espaços escolares, deve-se atentar para uma relação dos domínios da culturas, áreas do conhecimento e as ciências de referência para que eles sigam uma lógica em relação aos métodos empregados, sem perder de vista o propósito do ensino e aprendizagem atribuído aos alunos, ou seja, a “dimensão didática do processo pedagógico" (SAVIANI, 2000, p. 11).

Os conteúdos apresentados pelos professores aos alunos é uma opção histórica configurada, que se desenhou dentro de uma determinada trama cultural, político, social e escolar (SACRISTÁN, 2000). Essa realidade prática atribuída a escola pode ser analisada por diversos pontos conectados sobre o currículo. O currículo é a expressão de uma série de determinações atribuídas a uma prática escolar; sendo o currículo vários conteúdos que são sequenciados em determinados materiais por meio de saberes distribuídos pelos professores em suas aulas.

Assim, no currículo existe um campo de interação entre escola, professor e aluno, que exerce uma conexão da prática curricular com o conteúdo. "O currículo modela-se dentro de um sistema escolar concreto, dirige-se a determinados professores e alunos, serve-se de determinados meios, cristaliza, enfim, em um contexto, que é o que acaba por lhe dar o significado real" (SACRISTÁN, 2000, p.21). Por isso, a defesa na teoria do tipo crítica evidencia as realidades que o condicionam, condicionando a prática exercida pelos professores no processo de ensino e aprendizagem.

O campo do currículo, para Saviani (2000), fundamenta-se em uma disputa política, apresentando normas inseridas no ambiente escolar que enfatizam o processo pedagógico dentro da escola, pautado 
ISSN 1983-1579

Doi: 10.22478/ufpb.1983-1579.2020v13n1.51278

http://periodicos.ufpb.br/ojs2/index.php

na relação entre o currículo e a didática. A concepção de currículo como prática escolar e como ação atribuída nos espaços escolares, privilegia uma discussão sobre como acontece esse processo na escola. Outra questão importante a ser colocada é a articulação do currículo como imposição impostas por sistemas que normatizam e estruturam a educação, fazendo o currículo uma estrutura por ligações conectadas ao processo educativo.

\subsection{Currículo como práticas escolares impostas}

Nessa compreensão de currículo como prática escolar outras questões aparecem; como o currículo torna-se uma estrutura de autoridade imposta pelos sistemas de educação. Nesse sentido, o currículo é imposto para as escolas, que acabam inviabilizadas por não terem a identidade da comunidade onde estão inseridas. Há ainda professores que ficam presos e submissos aos sistemas de imposição curricular devido às propostas de um currículo rígido que foge das realidades e das especificidades existentes. Esses currículos também determinam o que se deve ensinar e como ensinar seus alunos, atribuindo normas sobre o tempo e planejamentos dos docentes.

Trazendo essa teorização sobre o currículo como uma construção em disputa. Segundo Arroyo (2011), o currículo em sua construção histórica, política, social e ideológica, sempre foi marcado tratandose de um território em disputa, constituindo-se muitas vezes por uma camada hegemônica, atribuindo assim, imposições de uma camada dominante. Essa concepção crítica do autor sobre currículo salienta como o currículo é um campo de luta entre as práticas dos docentes e aquilo que é proposto ou imposto pelo sistema educacional. Por vezes, o professor vê-se preso a conteúdos que não possibilitam trabalhar com as reais necessidades dos alunos, isso acaba criando um certo aprisionamento na liberdade didática construída pelos professores.

Na concepção de Arroyo (2011), ao longo do tempo os sistemas regulam e normatizam os trabalhos docentes, mesmo existindo demais estudos críticos sobre o currículo, ainda se encontram vínculos entre poder e acumulação. Essas normas, que obedecem a ordenamentos sobre uma lógica tradicional, acabam criando uma segmentação dos alunos, bem como influenciam na avaliação e nas qualificações e classificações que medem os desempenhos do alunado, as quais obedecem a lógicas progressivas que apenas objetivam aprovar ou reprovar alunos e mestres (ARROYO, 2011).

Deve-se haver autonomia do docente em suas atividades dentro de sala de aula, pois o professor é um dos agentes fundamentais no processo de ensino-aprendizagem. Ele tem que ter, dadas as proporções, uma certa liberdade para trabalhar suas atividades em sala de aula, de acordo com o que os alunos necessitam, segundo o ambiente e a realidade deles. Entretanto, o professor acaba sendo impossibilitado de trabalhar de uma forma que se faça uma articulação mais adequada sobre determinado contexto cultural. A liberdade e autoria de professores, para Arroyo (2011), dão-se pelo direito de ensinar aos alunos um conhecimento que os liberte e que estude também questões do dia a dia deles, pois os docentes são atrofiados por um currículo que surge como um território em disputa entre sistema e professores. Ainda segundo o autor "é ético questionar por que o currículo passou a ser um território onde o conhecimento acumulado se afirmar como o único, legítimo, onde a racionalidade científica, se legitima como única racionalidade" (ARROYO, 2011, p. 40).

Como pode-se ver, os conhecimentos tidos como fundamentais para a formações dos alunos são atribuídos a partir de normatizações, que muitas vezes não ouvem as vozes dos verdadeiros agentes da educação, excluindo a opinião dos sujeitos participantes das propostas curriculares. Muitas vezes, os currículos como práticas escolares são construídos não reconhecendo a diversidade presente nos contextos escolares, negando muitas vezes culturas que estão presentes nesses espaços ou em comunidades em que a escola se instala. O currículo acaba fugindo das realidades locais e padronizando o processo educativo, que é construído para outras realidades, ignorando as comunidades - como as tradicionais - e suas especificidades culturais.

Trazendo essa relação das culturas negadas no currículo escolar, Santomé (1995) faz uma discussão sobre o campo do currículo escolar, a formação que os alunos terão no seu processo escolar e como o 
processo escolar é imposto por uma classe dominante que não dá visibilidade para as diferentes representações culturais e formas de saberes. $O$ autor leva em consideração a formação de muitos sujeitos que vivem fora dos espaços urbanos. Desse modo, ele declara que os currículos impostos a esses sujeitos não têm, em sua configuração, a identidade das pessoas que são o cerne no seu processo de educação e formação, não relacionando com suas formas de vida, trabalho, lazer, crença, e outras diferentes formas de conhecimentos (SANTOMÈ, 1995).

Já Giroux e Simon (2009) afirmam que a prática curricular deve ter como princípio uma pedagogia crítica que busque incorporar a experiência do aluno ao conteúdo curricular oficial. À vista disso, há a necessidade de uma concepção de currículo que englobe a realidade local, que possibilite ao aluno conhecer a si mesmo e seu contexto, ou seja, o seu modo de vida, a sua cultura e sua identidade.

\subsection{Currículos e alguns desafios da/na Educação do Campo}

A educação no campo demanda, além de sua estrutura física e curricular, uma construção sempre diferenciada da educação voltada para os espaços urbanos, sendo relevante considerar sua estrutura política e curricular, enfatizando as propostas pedagógicas que cada instituição escolar e órgãos normativos vão despenhar em sua realidade local. A educação do campo, tratada como educação rural na legislação brasileira, tem um significado que incorpora os espaços da floresta, da pecuária, das minas e da agricultura, mas os ultrapassa ao acolher em si os espaços pesqueiros, caiçaras, ribeirinhos e extrativistas. O campo, nesse sentido, é "mais do que um perímetro não-urbano, é um campo de possibilidades que dinamizam a ligação dos seres humanos com a própria produção das condições da existência social e com as realizações da sociedade humana" (BRASIL, 2002, p. 267).

As Diretrizes Curriculares Nacionais da Educação Básica revistada em 2013 defendem uma educação para a população rural adequada às peculiaridades da vida no campo e de cada região. Define orientações para três aspectos essenciais à organização da ação pedagógicas:

I-Conteúdos curriculares e metodologias apropriadas às reais necessidades e interesses dos estudantes da zona rural;

II - Organização escolar própria, incluindo adequação do calendário escolar às fases do ciclo agrícola e às condições climáticas;

III - adequação à natureza do trabalho na zona rural. (BRASIL, 2010. p.45)

Conforme é estabelecido no documento que direciona a educação no do campo, onde vem promover nas escolas do campo uma educação pautada na identidade da população que trabalha com os ciclos da natureza e com os conhecimentos da terra, privilegiando as formas de trabalho, linguagens, saberes e fazeres, entre outras formas de conhecimentos culturais presentes no meio rural. Ainda, as DCNEC (Diretrizes Operacionais para a Educação Básica nas escolas do campo) (2010) constitui a valorização da identidade das populações do campo por meio do currículo como meio de potencializar dentro da escola os aspectos culturais do campo e o respeito a realidade local.

Perante os grandes avanços das políticas públicas para a educação no campo, bem como o investimento financeiro, a realidade ainda é bem diferente comparada a escolas na zona urbana. Sob um olhar atento, torna-se injustificável a manutenção de uma escola pública situada no campo sem ela ter condições mínimas e adequadas de infraestrutura. Pode-se notar também os poucos esforços do poder público para garantir uma educação escolar de qualidade nessas regiões; há ainda uma política educacional precária em relação ao atendimento desses espaços, à infraestrutura, aos materiais básicos de limpeza, aos livros e materiais didáticos, bem como à formação de professores (HAGE; BARROS, 2010).

Ao constatar-se a presença de políticas públicas que são pautadas em direcionamentos para uma organização de um trabalho pedagógico nas escolas do campo, pode-se observar que ainda existe limites em garantir a qualidade da educação do campo. Além de situações que, Hage e Barros (2010, p.352) enfatizam, "que envolve fortes repercussões sobre o fracasso escolar dos sujeitos do campo, expresso nas taxas elevadas de distorção idade-série, de reprovação e de dificuldades de aprendizagem da leitura e escrita" de escolas do campo. As políticas educacionais para a educação do campo muitas vezes não vão ao encontro do que essas comunidades necessitam ou muitas vezes não chegam a acontecer de fato. 
ISSN 1983-1579

Doi: 10.22478/ufpb.1983-1579.2020v13n1.51278

http://periodicos.ufpb.br/ojs2/index.php

Percebe-se que é necessária uma postura do estado, que viabilize na prática, uma educação que trate de dialogar com as realidades presentes, fortalecendo e valorizando os trabalhos existentes nesses aspectos sociais. A educação do campo encontra muitas barreiras, por exemplo, currículo homogêneo e universalizado, proposto em um sistema de ensino a partir da visão urbana, sem considerar os saberes culturais presentes nas comunidades escolares. Além da grande precariedade do ensino como um todo, falta de formação inicial e continuada de professores, entre outros fatores que dificultam uma educação adequada para os sujeitos do campo.

\subsection{Educação do Campo na Amazônia}

A educação do campo atravessa historicamente diferentes espaços em sua construção, permeado não só pelos contextos agrícolas, mas sobre diferentes contextos, sendo assim, na Amazônia ela é mediada por diferentes territorialidades; campos, costeiro, quilombolas, pesqueiros, ribeirinhos, povos das florestas, etc. Para Hage e Barros (2011), as diferentes concepções sobre a educação do campo na região Amazônica são manifestadas pelas classes multisseriadas em diferentes contextos e ecossistemas. Grande parte das escolas do campo trabalham em classes multisseriadas, sendo a forma de organização para escolas situadas fora dos espaços urbanos. As escolas do campo que trabalham com classes multisseriadas reúnem estudantes de diversos níveis e séries em uma mesma turma, e sendo responsável pela turma apenas um professor. Sendo assim, um professor que trabalha em uma classe multisseriada tem que articular um planejamento para três turmas ou mais ao mesmo tempo, respectivamente. As escolas que utilizam das classes multisseriadas são geralmente a única opção para os sujeitos das comunidades terem a sua escolarização. Além disso, tem o fator infraestrutura que não supre as demandas das classes multisseriadas, conforme Hage (2014, p. 1172) enfatiza:

Ao associarmos essas deficiências na formação ao fato de que esses educadores desenvolvem o trabalho docente em condições pouco adequadas, onde as escolas possuem infraestrutura precária e funcionam em prédios muito pequenos, em péssimo estado de conservação e, em muitas situações, não possuem nem mesmo prédio próprio e funcionam em salões de festas, barracões, igrejas, em um único compartimento onde se realizam as atividades pedagógicas e todas as demais atividades que envolvem os sujeitos da escola e da comunidade.

A região Amazônia apresenta uma rica diversidade de povos, comunidades e territórios, deparando-se com uma grandiosa pluralidade de ecossistemas. Para Hage e Barros (2010), é importante ter um olhar específico e particular nas escolas inseridas nos espaços da Amazônia, buscando um modo característico de analisar o currículo dessas escolas. Diante disso, a educação do campo na Amazônia tenta, em sua dinâmica, refletir sobre a realidade em que está inserida, buscando assumir uma missão de condutora de identidade e de sentimento de pertencimento. A proposta pedagógica de uma escola nesse contexto deve estruturar um pensamento crítico da realidade, que tenha como proposta formar sujeitos que tenham uma escolaridade adequada e que possam buscar outros mecanismos de subsistência dentro da comunidade respeitando seus costumes e seus modos de vida.

Nessa vertente sobre a educação no campo é importante considerar a importância de uma educação no lugar onde essas pessoas vivem, e considerando o seu contexto e seu modo de vida. Segundo Caldart (2000), as comunidades e populações do campo têm total liberdade e direito por políticas que subsidiem os seus direitos a uma educação que seja no e do campo. Para Caldart (2009, p. 51), "a Educação do campo se construiu pela passagem em política produzida nos movimentos sociais para o pensar/pressionar pelo direito do conjunto dos camponeses ou dos trabalhadores do campo".

Sendo assim, é importante trazer uma discussão que venha dialogar sobre os currículos propostos nessas escolas, buscando trazer a concepção de currículo como prática escolar. Enfatizando também o amplo campo teórico existente do currículo, buscando-se trazer uma discussão sobre o currículo proposto que interaja com as especificidades locais, bem como sobre quais as barreiras dentro do currículo que impedem essa interação com a realidade local dos sujeitos. 


\section{PERCURSO METODOLÓGICO DA PESQUISA}

A pesquisa é do tipo de abordagem qualitativa por buscar articular entre os sujeitos interlocutores e objeto estudado. A abordagem qualitativa na perspectiva de Bauer, Gaskel e Allum (2002) tem vários propósitos em uma investigação, condizendo para estabelecer uma base de autocrítica e análise, dando suporte e autonomia, objetivando credibilidades da pesquisa quali.

Em uma pesquisa qualitativa é importante considerar os instrumentos para a coleta dos dados, pois "todos fenômenos são dados igualmente importantes e precisos" (CHIZZOTTI, 2010, p. 84). A pesquisa utilizou a entrevista com roteiro e uso de recursos tecnológicos para gravação de áudios e o diário de campo, além de um roteiro de perguntas entregue para as professoras.

A escolha da pesquisa qualitativa vem dar mais ênfase nas abordagens propostas pelos objetivos do estudo, possibilitando ver na pesquisa das ciências humanas, a importância de ouvir agentes que participam do processo educativo de uma escola rural situada em uma comunidade tradicional. Buscando analisar nas falas dos colaboradores da pesquisa como acontece essa relação entre o currículo e os saberes culturais dentro do espaço escolar. Trazendo essa discussão de análise para o campo teórico. Também a escolha da pesquisa qualitativa se dá pelo fato do objeto ser ressignificado por um fenômeno social, atribuído a falas de sujeitos que participam de um processo formativo e educativo dentro do contexto escolar.

\subsection{Comunidade da Vila Que Era}

A pesquisa foi realizada na Comunidade da Vila-Que-Era, um espaço relevante socialmente, cultural e histórico para a cidade de Bragança, Estado do Pará, principalmente, porque deu origem à cidade de Bragança, localizada às margens do Rio Caeté, nome de origem indígena. A cidade de Bragança do Pará, uma das mais antigas do Estado do Pará, com mais de 400 anos de existência, tem como primeiros habitantes os índios, sendo colonizada pelos portugueses. Historicamente, a cidade recebeu muitos imigrantes, como espanhóis, africanos e brasileiros de diversas regiões, que contribuíram para a formação do povo bragantino, para a diversidade cultural, exercida com costumes, crenças religiosas, etnias etc. Possibilitando a formação das comunidades tradicionais que cercam a cidade, sendo territórios com diferentes ecossistemas e diversidades espacial e cultural.

A região bragantina, em sua configuração ao longo do tempo, caracterizou-se por ser uma cidade com uma riqueza cultural histórica, reconhecida como uma cidade tradicional e histórica, pela festividade de São Benedito e pela marujada. A Pérola do Caeté, como é conhecida, apresenta em seu entorno comunidades tradicionais com características culturais herdada dos seus primeiros habitantes, diferentes comunidades com diferentes formas de organização e estrutura, comunidades como o Quilombo do América, a comunidade pesqueira da Vila dos Pescadores, e a Comunidade da Vila-Que-Era, sendo a comunidade pesquisada.

Conforme é mostrado no estudo de Sílvia Oliveira (2013) no seu trabalho de dissertação intitulado "memórias de saberes construídos no processo de se constituir professor em vila que era (bragança-pará)"3, a autora em seu estudo realizado na comunidade, possibilita conduzir características existente na comunidade. A autora constata, que a comunidade da Vila-Que-Era, "fica situada a $8 \mathrm{~km}$ da cidade de Bragança, possui cerca de aproximadamente 350 habitantes, caracteriza-se por viver economicamente de atividades agro-pesqueira" [...] (OLIVEIRA, 2013, p.25). Para Oliveira (2013, p.25) "A referida Vila carrega consigo a conservação de traços culturais históricos investindo na preservação de suas raízes culturais como: os saberes tradicionais na área medicinal, profissional e outros saberes". Saberes que podem ser traduzidos em diferentes categorias, como a pesca, agricultura, culinária, saberes místicos entre outros.

O lider comunitário ${ }^{4}$ informou que o lugar preserva "a cultura e a história, onde tem muita coisa

3 Dissertação apresentada ao Programa de Pós-Graduação em Linguagens e Saberes na Amazônia- PPLSA. Com a autoria de Sílvia do Nascimento Oliveira, no ano de 2013.

${ }^{4}$ A pesquisa teve a participação do Líder comunitário da Comunidade da Vila Que Era, proporcionando informações sobre a organização da Vila. Atribuindo informações sobre os saberes culturais existentes na comunidade. 
ISSN 1983-1579

Doi: 10.22478/ufpb.1983-1579.2020v13n1.51278

http://periodicos.ufpb.br/ojs2/index.php

bonita [...]". Para ele os saberes culturais são traduzidos pela pesca artesanal, extração do caranguejo, cultivo de plantações, produção da farinha de mandioca, criação de animais, cultivo de plantas medicinais, entre outras formas. Como tradição, a Comunidade tem outras formas de saberes culturais como a confecção do abano, do paneiro ${ }^{5}$ e a meaçaba ${ }^{6}$,entre outros objetos como a panela de barro. A representatividade religiosa se faz presente pelos saberes místicos em relação à natureza e sobre os fenômenos da natureza e religiosidade, existindo uma grande festa religiosa na comunidade.

Esses elementos culturais forjam a identidade cultural da população da comunidade da Vila-QueEra, em que os moradores mostram pertencimento nas territorialidades do local e em seus modos de vida. Percebe-se a grande identidade representada na comunidade, através dos saberes culturais que é vivenciado na localidade, possibilita uma estrutura que organiza as atribuições que a comunidade exerce.

Figura 1: E. M. E. I. F. Maria Helena Santos Aviz / Vila-Que-Era.

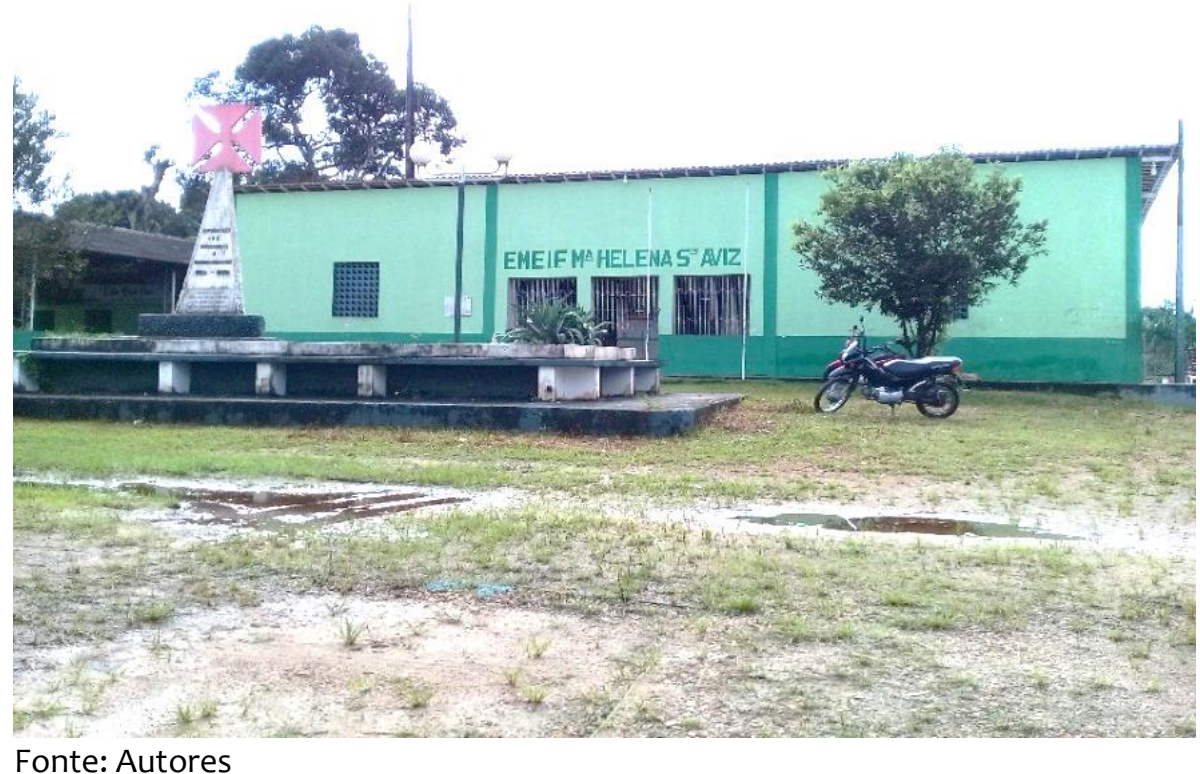

\section{ACHADOS DO ESTUDO}

Em meio a análise e discussão sobre o currículo e a relação com os saberes culturais presentes nos espaços escolares no contexto da comunidade da Vila- Que-Era, foram atribuídas às professoras perguntas referente ao currículo trabalhado na escola da vila, reportando sobre como acontece o trabalho pedagógico na escola e a organização da proposta curricular. E como acontece a relação do currículo escolar com os saberes culturais da comunidade, e como as professoras efetivam essa prática

\footnotetext{
${ }^{5}$ Uma estrutura feita de palha seca, em forma de sacola ou gaiola, sendo usada de várias formas.

${ }^{6}$ Uma forma de artesanato feito de palha seca, utilizado como uma forma de cortina, dependendo da sua utilidade.
} 
no contexto da escola.

As Professoras revelaram um currículo com base dos temas geradores na perspectiva de Paulo Freire, atribuído pela secretaria municipal de educação, sendo uma proposta enfatizada por Freire que busca essa articulação entre o cotidiano do educando, na possibilidade de trabalhar junto às necessidades do mesmo. Freire (1993) considera que os temas geradores veem ao encontro do ponto de partida de uma racionalidade sobre um diálogo sistematizado, atribuindo conhecimento junto ao que é vivido pelo educando, trabalhando assim, um diálogo interdisciplinar e uma possibilidade de articular outras formas de conhecimentos.

Outras questões colocadas pelas professoras é a questão do trabalho realizado nas turmas multisseriadas. Enfatizando as dificuldades existentes no contexto de uma escola do campo, que vão desde o aspecto físico até os organizacionais, além das turmas com diferentes perfis de alunos. Segundo o relato de uma das professoras, escola que antes que tinha como responsabilidade o governo do estado, passou a ser administrada pelo governo do municio, mediante a problemas de gestões passadas. Ocasionando assim, uma falta de recursos para a escola, até hoje a escola ainda sofre com essa mudança administrativa. $\mathrm{O}$ que eventualmente faz a escola receber normas curriculares impostas pela secretaria municipal de educação de Bragança, Pará. Através dos dados obtidos pelas professoras foi estabelecido duas categorias de análise interpretativa, trazendo assim, a fundamentação de como acontece essa interação entre os saberes culturais e o currículo trabalhado pelas professoras no seu dia a dia no trabalho de ensino/aprendizagem; sendo os saberes culturais nas práticas curriculares e o currículo escolar e a relação com os saberes culturais.

\subsection{Saberes culturais nas práticas curriculares}

Nas análises, buscou-se trazer uma discussão sobre o currículo e a sua articulação com os saberes culturais na escola da comunidade, analisando como essa interação acontece na escola. A princípio em relação à proposta da pesquisa, percebe-se que a temática currículo ainda de certa forma provoca uma resistência ao se falar no espaço escolar, exercendo um recuo por parte dos entrevistados sobre o que pretende analisar no currículo. Atualmente falar de currículo ainda é um aspecto que incomoda, principalmente relacionado à educação básica, talvez pelas discussões que é alavancado por ele, sendo muitas vezes uma crítica ao próprio sistema que é imposto nas escolas e nas realidades escolares.

À vista disso, perguntou-se sobre como é trabalhada na escola a articulação entre os saberes locais e as práticas vivenciadas no currículo da escola. As professoras, consideram a importância de um trabalho que seja vinculado à realidade da comunidade, buscando trazer a importância cultural que a vila detém, atribuindo a um currículo integrado.

Perguntado as professoras como acontece esse currículo integrado, elas constataram que buscam atribuir às vivências dos alunos, mas devido ao fato das turmas terem diferentes níveis de séries, não acontece essa proposta, advindo de outros fatores, como a falta de apoio da secretaria de educação, com materiais e com formações. Além disso, uma das professoras colocou da seguinte forma, que no planejamento busca-se "Desenvolver as atividades partir da realidade dos saberes dos educandos, procurando encaixar dentro do currículo as práticas vivenciadas".

Buscou-se também, saber junto às professoras, como acontece a interação dos saberes locais com os conteúdos curriculares repassados aos alunos. As professoras informaram que elas utilizam-se de um planejamento individual pelo fato de trabalharem em séries diferentes, assim cada uma delas faz um planejamento que englobe as turmas e faixa etária dos seus alunos. Segundo uma das professoras: "Essa interação acontece através do planejamento e sequência a didática bimestral".

Percebe-se que, segundo as falas das professoras, é executado um planejamento individual pelo fato de trabalharem em turmas diferentes, observa-se a falta de um planejamento coletivo, ou então de uma construção de um projeto que a escola irá executar no decorrer de seu ano letivo. Constatando assim, uma dificuldade de fazer um trabalho articulado com outras turmas, como projetos que vão atribuir a participação de todas as turmas e da comunidade. Projetos que podem trazer dentro deles uma proposta que venha dialogar com os saberes culturais existentes na comunidade. 
ISSN 1983-1579

Doi: 10.22478/ufpb.1983-1579.2020v13n1.51278

http://periodicos.ufpb.br/ojs2/index.php

Ressaltando que para de fato acontecer a proposta baseada nos temas geradores de Paulo Freire (1993) precisa a escola criar temas que debruce sobre a realidade da escola, ou de problemas que a comunidade vivencia, mas a princípio na realidade ainda falta essa articulação.

Ou então, um planejamento que traga uma proposta curricular que busque essa interação entre os saberes culturais existentes na comunidade; como aulas passeios, projeto de horta orgânica, uma proposta sobre a importância da pesca artesanal para a comunidade, respeito às diversidades e dos ciclos da natureza, por meio de outras formas de dar uma real atenção aos aspectos existentes na comunidade.

Em uma das falas também se considerou a importância das diversas formas para se trabalhar de uma maneira em que se possa interagir com o contexto local; segundo a professora que trabalha do $1^{\circ}$ ao $3^{\circ}$ do Ensino Fundamental:

São contação de histórias, produção de textos com todos os gêneros, criação de desenhos, leitura e interpretação, palestras, confecções de cartazes, atividades escritas, pesquisas (bibliográfica e de campo), músicas, brincadeiras, vídeos e outros (professora do $1^{\circ}, 2^{\circ}$ e $3^{\circ}$ ano).

Percebe-se, tentativas e diversas alternativas para integrar no currículo a um trabalho que possa articular com as peculiaridades existentes dentro da comunidade. Como já foi colocado anteriormente, a comunidade da Vila Que Era exerce diversas atividades como pesca, artesanato, extrativismo, religiosidade, mitos, cultivo de plantas medicinais, entre outras formas que podem ser atribuídas nas práticas dentro da sala de aula, possibilitando estudar e compreender os diversos saberes culturais que a comunidade exerce.

Mediante a resposta da professora, o que se pode analisar é a dificuldade em trabalhar de uma forma que venha articular com o cotidiano dos alunos da escola da Vila Que Era, percebe-se que, no que ela informou, são práticas geralmente encontradas em uma escola urbana. Entretanto, é necessário um trabalho diferenciado, buscando vincular uma proposta de interação com os saberes culturais da vila, é importante atribuir um planejamento curricular que venha trazer questões que são trabalhadas na vila, como a pesca, a agricultura, a história da vila. A escola precisa criar uma autonomia sobre a sua proposta curricular, sendo que a mesma está em uma comunidade que tem uma característica própria e rica de diferentes formas de saberes culturais, encontra-se ainda um currículo urbano-centro nas propostas da escola.

Reportando a fala da professora, apoiando-se na ideia de que o docente é um agente fundamental no processo de ensino/aprendizagem, atribuindo a ele a decisão de uma contracorrente do sistema, livre em sua prática, fugindo de determinações que se desvinculam de direitos sociais e educacionais. Dentro dessa perspectiva o professor é aquele possibilita alternativas sobre sua prática dentro da sala de aula, ele tem total direito e autonomia de buscar novas alternativas que vão ao encontro de seus alunos, atribuindo possíveis movimentos contrários contra um currículo homogêneo e estático.

Buscando analisar quais as dificuldades em atribuir um currículo que faça esse movimento com os saberes culturais locais, buscou-se saber junto as professoras, qual as alternativas elas exerciam para fazer essa inter-relação. A pergunta feita para as professoras foi em relação às dificuldades existentes para se trabalhar de uma maneira que o currículo interaja com esses saberes culturais presente na comunidade. Em uma das falas, notou-se que os problemas sempre são iguais ao que acontece em outras comunidades envolvendo a educação no campo, a fala foi a seguinte: "Falta de apoio com materiais didáticos, espaços físicos adequados (muro da escola) outros".

A Educação no Campo enfrenta diversos problemas em comparação à educação dos perímetros urbanos, principalmente em relação aos suportes de material didático adequado e infraestrutura. Outra situação problemática é em relação a multissérie, que de certa forma é uma educação diferenciada e requer uma didática específica, muito diferente ao que acontece nas escolas urbanas. Segundo Chizzotti e Silva (2018), o trabalho atribuído as classes multisseriadas não se limita apenas a um trabalho de um grupo diversificado de alunos, pois trabalhar-se com diferentes turmas ao mesmo tempo necessita de 
uma didática totalmente diferenciada; além do mais, enfrenta-se problemas com uma infraestrutura inadequada e com professores que não têm uma formação para lidar com a multissérie.

Trazendo essa constatação da realidade encontrada na multissérie e na educação do campo, Hage e Borges (2010), enfatiza em seus estudos que a educação do campo e a escola multisseriada ainda vivenciam situações totalmente desiguais; não havendo uma educação de qualidade e com dignidade, sendo que essas situações podem envolver o fracasso escolar, pois há expressivos números relacionados à distorção idade-série, reprovação e dificuldades na aprendizagem dos alunos. Ocasionando também uma sobrecarga aos professores que trabalham nesses contextos, assumindo, por vezes, funções como a de faxineiro, diretor, secretário, merendeiro, entre outras atribuições (HAGE: BORGES, 2010).

Outra situação bastante pertinente relatada pelas professoras é em relação a funcionalidade da escola, sendo que escola da pesquisa é anexa de outra escola rural. Então, percebeu-se uma certa dependência quando aos procedimentos de gestão da escola, ou seja, falta uma certa autonomia. Questões que muitas vezes envolvem decisões colocadas na outra escola são atribuídas para a escola Maria Helena Santos Aviz, impossibilitando ouvir também a voz da comunidade local em relação ao planejamento escolar. Apesar disso, as professoras tentam e suas práticas diferentes formas de estratégias e articulação, quanto as dificuldades encontradas na escola da comunidade.

\subsection{Currículo Escolar e a relação com saberes culturais}

Mediante ao processo da pesquisa, observou-se uma certa dificuldade em relação as professoras em relatar sobre o currículo presente na comunidade da Vila Que Era, talvez por ser uma temática ainda polemica pelo ponto de vista das professoras, ou então, por se tratar de uma questão que envolve formações continuadas, ou até mesmo por questões profissionais referentes a contrato. Atribuído assim uma certa resistência das professoras em responder sobre o currículo trabalhado na escola.

Como foi observado a escola apresenta questões que vão de encontro às barreiras que impossibilitam um currículo que venha articular com os saberes culturais da comunidade. Sendo questões físicas, entre normas impostas pela secretaria de educação e de formações continuada de professores.

Outrossim, percebe-se questões pertinentes que acontecem com frequência na realidade das escolas fora da cidade, como por exemplo um currículo urbano-centro, ou seja, um currículo centrado e construído para os sujeitos da cidade. Os currículos atribuídos a escolas do campo tentam, em sua proposta, ter uma articulação com a identidade local; porém nos relatos das professoras, a realidade ainda está longe de uma inter-relação completa, pois as propostas das secretarias de educação vêm como uma linha inversa, voltadas apenas para o conteúdo clássico das escolas urbanas. Segundo Arroyo (2011), as esferas controladoras da educação tornam-se totalitárias em suas gestões e avaliações, propondo um currículo por competências, que controla os professores e imponha um currículo único, sendo um padrão mínimo e único de qualidade.

A intenção de uma proposta para educação do campo é em trabalhar com as especificidades da realidade do aluno, mas sem fugir de uma educação de direito. Para Arroyo (2011), uma educação que articula com as especificidades do aluno não tem como objetivo desviar o foco do que o processo formativo pretendido. Não se trata de uma forma de se desvincular o direito a uma educação intelectual cientifica, estética e crítica, mas de atrelar os saberes de si mesmo, reconhecendo outras formas de produção de conhecimento. O trabalho realizado nas escolas torna-se um importante condutor social, considerando assim uma formação sujeita a uma interação com a sociedade, pois tudo o que se aprende dentro da sala de aula é vivido no social simultaneamente.

Sobre os saberes culturais presentes no contexto escolar, olhando especificamente para os currículos, ainda há com uma certa objeção quanto a articulação com os saberes culturais presentes no contexto local. Observa-se ainda que muitos currículos que são universalizados, não se moldando às especificidades dos contextos em que as escolas de comunidades tradicionais estão inseridas.

Diante da necessidade dos números e medição dos sistemas de educação em avaliar professores e alunos, ocasiona-se uma ordenação de uma educação estática e cristalizada. O currículo sofre uma conduta que não o torna flexível, muitas vezes impossibilitando o acontecimento da interação entre os 
ISSN 1983-1579

Doi: 10.22478/ufpb.1983-1579.2020v13n1.51278

http://periodicos.ufpb.br/ojs2/index.php

saberes culturais e os conhecimentos científicos escolares. Na perspectiva de Sacristán (2000, p. 17), “o currículo reflete o conflito entre os interesses dentro de uma sociedade e os valores dominantes que regem os processos educativos". Por esse motivo, é necessário buscar algumas alternativas e estratégias para enfrentar essas situações de dificuldades encontradas entre a relação o currículo e os saberes culturais.

A formação continuada de professores é uma saída importante para essas questões, possibilitando a eles conhecimentos e base para que criem possibilidades de alternar as práticas e didáticas em escolas do campo. Assim sendo, o docente torna-se um importante agente nessa articulação entre o currículo e a flexibilidade de um currículo escolar dinâmico, sendo um agente que possa fugir das imposições de um sistema desigual e selecionista. No pensamento de Pimenta (2008), o professor deve fugir das universalizações impostas por um sistema que não trabalha as especificidades presentes no contexto escolar. Essas universalizações, por vezes, estão aquém das realidades das quais as escolas estão inseridas, principalmente as escolas de fora do contexto urbano. A crítica de Pimenta (2008) contribui para a reflexão e estudo sobre como um professor, que atua em uma comunidade tradicional, trabalha a questão dos saberes culturais com os conhecimentos escolares.

Outro fato que é importante ser analisado, é a questão que as professoras residem na sede da cidade, e vão para a comunidade apenas nos horários da aula, então necessita de uma participação na comunidade. Nessas realidades o professor torna-se um líder e um mediador, necessitando essa articulação com a comunidade e a escola.

Por conseguinte, é necessário trazer esses diálogos entre os saberes culturais e o currículo escolar, buscando discussões que possam trazer novas possibilidades e análises na projeção dessa temática. A realidade da escola da Vila Que Era é uma entre as diversas escolas espalhadas pelos territórios da Amazônia e do Brasil. Trazendo sobre a questão do currículo, constata-se que os currículos impostos pelas secretarias de educação ainda são currículos totalmente desiguais e totalitários, que enfatizam somente as camadas dominantes, não atribuindo às suas propostas a identidade de escolas fora do perímetro urbano. Falta formações iniciais e continuada de professoras que venham dar suporte para eles ter subsídios em escolas fora do parâmetro urbano, possibilitando-os criar conhecimento e alternativas para articular o currículo trabalhado nas escolas com os saberes das localidades.

\section{CONSIDERAÇÕES FINAIS}

A discussão sobre currículo perpassa um campo de amplo debate e análise, sendo importante levar em consideração o foco em que a pesquisa foi introduzida. Trazer a temática do currículo e a relação com os saberes culturais de uma comunidade tradicional, proporcionou entender e adentrar algumas formas de análises e outros campos que podem ainda serem problematizados em demasia.

Contudo, o campo dos estudos curriculares pode ser compreendido por diferentes formas de estudos e de linhas de pensamento, dentro disso as possibilidades que esses estudos trazem é importante para se construir uma visão crítica sobre a atualidade e como se ordena o sistema escolar, a construção teórica e pedagógica da escola, bem como a sociedade em que ela está inserida e como acontece essa ligação entre escola e o meio social.

O currículo, como prática escolar, direciona o que será trabalhado dentro das escolas, sendo ele um condutor do que será trabalhado na escola durante o calendário escolar, direcionando os conteúdos que serão repassados para os alunos, trazendo nas disciplinas os conhecimentos que os alunos levaram em seu processo formativo.

Entretanto, a busca de trazer para o trabalho a escolas que são inseridas dentro dessas comunidades tradicionais possibilita descrever a grandiosa bagagem de saberes e de práticas culturais que elas carregam em seus contextos. Nessas escolas transitam muitas dificuldades que permeiam por uma educação nacional ainda bastante precária, com o governo, por vezes, não dando a devida atenção para essas escolas, e o porquê da não preocupação de uma educação bem estruturada para essas 
comunidades, são indagações que atravessam décadas.

A discussão da teoria crítica do currículo permeia por diferentes campos de debate, buscando atribuir um livre debate de ideias e concepções sobre a autônima do professor dentro das escolas. Devese haver possibilidades de um trabalho didático que possibilite sair dos rituais propostos pelas diretrizes curriculares e de uma base comum desigual.

A escola onde a pesquisa foi feita trabalha com a educação do campo, e nela necessita-se trazerem propostas curriculares e políticas efetivas para a educação no campo. Percebe-se ainda grandes dificuldades nas escolas do campo, e na escola da comunidade da Vila Que Era, não é diferente. Nessa escola há problemas que afetam significativamente a aprendizagem dos alunos e o seu processo formativo, além de uma formação interligada com a realidade local.

Outra questão são as barreiras que impossibilitam um currículo articulado com os saberes culturais locais. Pois não há no currículo uma identificação dos sujeitos quanto a sua realidade local. Há ainda problemas de infraestrutura e de materiais didáticos, bem como os currículos que são propostos para os centros urbanos, mas que são repassados para escolas do campo.

Diante do exposto, é importante considerar a importância de um estudo que possibilite uma análise no currículo junto aos sabres culturais locais. Além disso, trazer as especificidades encontradas em cada contexto, as diferentes formas de organização, trabalho e socialização. Cada escola inserida nesses espaços precisa ter suas próprias características e autonomia respeitadas.

Mediante a tudo que foi colocado no artigo e frente aos ainda poucos trabalhos que abordam a temática em questão, esse trabalho tem uma grande relevância para futuras análises e discussões sobre a relação currículo e dos saberes culturais. Pode-se ainda, futuramente, serem feitas diferentes formas de abordagens e de discussões que possam trazendo outras formas de contribuição e respectivamente críticas.

Por fim, nota-se que é necessário trazer algumas alternativas que possibilitem essa articulação entre o currículo e a relação com os saberes culturais locais. A formação inicial e continuada de professores é uma alternativa para dar suporte aos educadores que trabalham nessas especificadas. Além disso, é fundamental o incentivo de políticas públicas que deem mais visibilidade para escolas fora do contexto urbano, bem como suporte didático e estrutural, buscando também dar mais autonomia para as escolas da zona rural, possibilitando uma educação com a sua identidade e uma formação escolar com dignidade e senso crítico quanto a sua própria realidade.

\section{REFERÊNCIAS}

ARROYO, Miguel. Currículo, território em disputa, Petrópolis: Vozes, 2011.

BAUER, Martin; GASKELL, George. ALLUM, Nicholas. Qualidade, quantidade e interesses do conhecimento- evitando confusões. In: BAUER, Martin; GASKELL, George (ed.). Pesquisa Qualitativa com texto, imagem e som: Um manual prático. Petrópolis: Vozes, 2002. Cap 1. P. 17-36.

. Análise de conteúdo clássica: Uma revisão. In: BAUER, Martin. GASKELL, George (ed.). Pesquisa Qualitativa com texto, imagem e som: Um manual prático. Petrópolis: Vozes, 2002. Cap. 8 p.189-217.

BRASIL. Lei $N^{\circ}$ 13.415, De 16 de fevereiro de 2017. Altera as Leis $n^{\circ}$ 9.394, de 20 de dezembro de 1996, que estabelece as diretrizes e bases da educação nacional, e 11.494, de 20 de junho 2007. Disponível em: http://www.planalto.gov.br/ccivil_03/_Ato2015-2018/2017/Lei/L13415.htm. Acesso em: 28 de fev de 2019.

. Base Nacional Comum Curricular (BNCC). Educação é a Base. Brasília, MEC/CONSED/UNDIME, 2017. Disponível em: < 568 http://basenacionalcomum.mec.gov.br/images/BNCC_publicacao.pdf>. Acesso em: 28 de fev. 2019.

- Constituição da República Federativa do Brasil. Brasília, DF: Senado Federal: Coordenação de Edições Técnicas, 2016. 496 p. Brasília, 1988.

.. Ministério da Educação. CNE/CEB Resolução CNE/CEB nº 01, de 03 de abril de 2002. Brasília, 2002.

. Ministério da Educação. CNE/CEB Resolução CNE/CEB nº 04, de 13 de julho de 2010. Brasília, 2010. 
ISSN 1983-1579

Doi: 10.22478/ufpb.1983-1579.2020v13n1.51278

http://periodicos.ufpb.br/ojs2/index.php

. Lei n6040, de 7 de fevereiro de 2007. Institui a Política Nacional de DesenvolvimentoSustentável dos Povos e Comunidades Tradicionais. Disponível em:<http://www.planalto.gov.br/ccivil_03/_ato20072010/2007/decreto/d6040.htm>. Acesso em 26/03/2019.

CALDART, Roseli Salete. A escola do campo em movimento. In: BENJAMIN, César. CALDART, Roseli Salete. (Org.) Projeto popular e escolas do campo. Articulação Nacional por uma educação do campo. v. 3. 2. ed. Brasília: UnB, 2000.

. Educação do campo: notas para uma análise de percurso. Trab. Educ. Saúde, Rio de Janeiro, v. 7 n. 1, p. 35-64,mar./jun.2009.

CHIZZOTTI, Antonio.; Pesquisa em ciências humanas e sociais. 5. Ed - São Paulo: Cortez, 2001.

- SILVA, Rosa Eulalia Vital da. Base Nacional Comum Curricular e as Classes Multisseriadas na Amazônia. Revista e-curriculum, São Paulo, v.16, n.4, p.1408-1436 out./dez.2018.

EYZAGUIRRE, Indira. Elaborado com dados do Google Earth (sapefiles) e com o software ArcGiS 10.0. 2019.

FERNANDES, Daniel; FERNANDES, José. Guilherme. A “experiência próxima”: saber e conhecimento em povos tradicionais. Espaço Ameríndio, Porto Alegre, v. 9, n. 1, p. 127-150, jan./jun. 2015.

GIROUX, Henry; SIMON, Roger. Cultura popular e pedagogia crítica: A vida cotidiana como base para o conhecimento curricular. In: MOREIRA, Antonio Flavio; SILVA, Tomaz Tadeu da. (org.) Currículo, cultura e sociedade. 11 ed. - São Paulo, Cortez, 2009.

HAGE, Salomão Antônio Mufarrej. Transgressão do Paradigma da (Mult)seriação como referência para a construção da Escola Pública do Campo. Educ. Soc., Campinas, v.35, nº.129, p.1165-1182, Out.-Dez, 2014.

- BARROS, Oscar. Currículo e educação do Campo: Referencias para o Debate sobre a Multisseriação na Escola do Campo. Espaço do Curriculo, v.3, n.1, pp 348-362, março de 2010 a setembro de 2010.

- Classes Multisseriadas: desafios da educação rural no Estado do Pará/Região Amazônica. In: HAGE, Salomão Antônio Mufarrej. (Org). Educação do Campo na Amazônia: retratos de realidade das escolas multisseriadas no Pará. Belém: Gráfica e Editora Gutemberg, 2005.

LOPES, Alice Casemiro; MACEDO, Elizabeth. (org.) Currículo debates contemporâneos. zed. São Paulo. 2005.

MOREIRA, Antonio Flavio. O campo de currículo no Brasil- origens e desenvolvimento inicial. In: MOREIRA, Antonio Flavio. Currículo e programas no Brasil. Campinas, SP; Papirus, 1990.

. SILVA, Tomaz Tadeu da; Sociologia e teoria crítica do Currículo: Uma introdução. In: MOREIRA, Antonio Flavio; SILVA, Tomaz Tadeu da; (org.) Currículo, cultura e sociedade. 11 ed. - São Paulo, Cortez, 2009.

OLIVEIRA, Silvia do Nascimento. Memórias de saberes construídos no processo de se constituir professor em Vila-Que-Era (Bragança-Pará). Bragança, Pará. Dissertação (mestrado em Linguagens e Saberes na Amazônia, 2013.

FREIRE, Paulo. Pedagogia do oprimido. São Paulo: Paz e terra, 1993.

PIMENTA, Selma Garrido. Professor reflexivo construindo uma crítica. In: PIMENTA, Selma Garrido; GHEDIN, Evandro (Orgs.). Professor reflexivo no Brasil: gênese e crítica de um conceito.- 5 ed.- São Paulo: Cortez, 2008.

SACRITÁN, José Gimeno. O Currículo: uma Reflexão sobre a Prática. 3. ed. Porto Alegre: Artmed, 2000.

SAVIANI, Nereide. Saber escolar e didática: problemas da unidade conteúdo/método no processo pedagógico. 3. ed. Campinas, SP: Autores Associados, 2000. 
SANTOMÉ, Jurjo Torres. Globalização e Interdisciplinaridade: o currículo integrado. Porto Alegre: Artes Médicas, 1998.

. As culturas negadas e Silenciadas no Currículo. In: SILVA, Tomaaz Tadeu. (org). Alienígenas na sala de aula: uma introdução aos estudos culturais em educação. 7. ed. Petrópolis, RJ: Vozes, 1995.

Recebido em: 23 de março de 2020

Aceito em: 14 de abril de 2020

Publicado em: 25 de abril de 2020 